\title{
EFEITO DA LUZ E DA TEMPERATURA NA GERMINAÇÃO DE SEMENTES DE AROEIRA (Myracrodruon urundeuva Allemão) ${ }^{1}$
}

\author{
Lígia Maria de Medeiros Silva², Teresinha de Jesus Deléo Rodrigues ${ }^{3}$ e Ivor Bergemann de Aguiar ${ }^{4}$
}

\begin{abstract}
RESUMO - Estudou-se a germinação das sementes de aroeira (Myracrodruon urundeuva Allemão) na presença e na ausência de luz, submetidas às temperaturas constantes de $10,15,20,25,30,35$ e $40^{\circ} \mathrm{C}$ e alternadas de $20-25$, 20-30 e 20-35 ${ }^{\circ} \mathrm{C}$. Os parâmetros avaliados foram a porcentagem, a velocidade e a frequiência relativa de germinação. As sementes de aroeira germinaram na presença e na ausência de luz, mas se revelaram fotoblásticas negativas preferenciais. A germinação foi nula a 10 e a $40{ }^{\circ} \mathrm{C}$, e a faixa de germinabilidade foi de 15 a $35^{\circ} \mathrm{C}$. No regime de temperatura constante, a faixa ótima para germinação das sementes foi de 20 a $30^{\circ} \mathrm{C}$. No regime de temperatura alternada, a melhor flutuação térmica para germinação das sementes foi a de $20-30^{\circ} \mathrm{C}$.
\end{abstract}

Palavras-chave: Sementes florestais, fotoblastismo e ecofisiologia.

\section{THE EFFECT OF LIGHT AND TEMPERATURE ON THE GERMINATION OF Myracrodruon urundeuva Allemão}

\begin{abstract}
Seed germination of Myracrodruon urundeuva Allemão (Anacardiaceae), a Brazilian native tree, was studied under two light conditions (light and dark), both at constant (10, 15, 20, 25, 30, 35 and $40^{\circ} \mathrm{C}$ ) and alternating $\left(20-25,20-30\right.$ and $\left.20-35^{\circ} \mathrm{C}\right)$ temperature regimes. Percentage, speed and distribution of germination were evaluated. Seeds germinated either in presence or absence of light, but showed to be preferable negative photoblastic. The germination was null both at 10 and $40^{\circ} \mathrm{C}$, but seeds germinated from 15 to $35^{\circ} \mathrm{C}$. The best germination occurred at constant temperatures from 20 to $30^{\circ} \mathrm{C}$, and alternating temperature of $20-30^{\circ} \mathrm{C}$.
\end{abstract}

Key words: $\quad$ Forest seeds, photoblastism and ecophysiology.

\section{INTRODUÇÃO}

O estudo da ecofisiologia da germinação permite a compreensão mais precisa dos processos que regulam a longevidade das sementes no solo e o estabelecimento das plantas em condições naturais (Vázquez-Yanes \& OrozcoSegovia, 1984). Segundo Dias et al. (1992), o entendimento da complexa regeneração de um ecossistema de floresta tropical reside na associação entre a germinação das sementes, marco inicial do ciclo sucessional, e o fator luz.
Em muitas espécies a presença de luz, de alguma forma, favorece a germinação das sementes, designando-se este efeito como fotoblástico positivo; em outras espécies o comportamento germinativo das sementes é melhor na ausência do que na presença de luz, o que se designa como fotoblastismo negativo (Labouriau, 1983). Klein \& Felippe (1991) denominaram o caráter fotoblástico positivo de "preferencial", quando alguma germinação ocorre na ausência de luz, e de "absoluto", quando a germinação é nula na ausência de luz.

1 Recebido para publicação em 7.2.2001.

Aceito para publicação em 3.12.2002.

2 Bolsista da FAPESP, doutoranda em Agronomia (Produção e Tecnologia de Sementes), Faculdade de Ciências Agrárias e Veterinárias, da Universidade Estadual Paulista - FCAV/UNESP, 14884-900 Jaboticabal-SP, <ligiamms@hotmail.com>; ${ }^{3}$ Bolsista do CNPq, Profa. Dra., FCAV/UNESP, <tedelro@fcav.unesp.br>; ${ }^{4}$ Bolsista do CNPq, Prof. Dr., FCAV/UNESP, <ivor@ netsite.com.br>. 
A germinação das sementes, em relação à luz, é uma resposta ecofisiológica da espécie, e tem estreita correspondência com o seu posicionamento no estádio sucessional da floresta (Jesus \& Piña-Rodrigues, 1991). As sementes de espécies pioneiras fotoblásticas respondem com germinação plena apenas quando são submetidas à luz vermelha, enquanto as pertencentes aos demais grupos ecológicos, como as secundárias e as clímax, têm a capacidade de germinar à sombra do dossel, sem luz solar direta (Kageyama \& Viana, 1991).

Em algumas espécies o requerimento de luz para germinação das sementes é fortemente influenciado pela temperatura (Smith, 1975), e a faixa de temperatura dentro da qual as sementes podem germinar é característica de cada espécie (Bewley \& Black, 1994). Os limites extremos de temperatura para germinação fornecem informações de interesse ecológico (Labouriau \& Pacheco, 1978), sendo importante a determinação das temperaturas mínima, ótima e máxima para cada espécie. A temperatura ótima propicia a máxima porcentagem de germinação em menor espaço de tempo, enquanto sob temperaturas máxima e mínima as sementes pouco germinam (Bewley \& Black, 1994).

Sementes de muitas espécies, principalmente as menos domesticadas, requerem flutuação diária de temperatura para germinar adequadamente. Embora esse requerimento esteja associado à dormência da semente, a alternância da temperatura pode acelerar a germinação em sementes não-dormentes (Malavasi, 1988).

Myracrodruon urundeuva Allemão é uma espécie arbórea pertencente à família Anacardiaceae, conhecida popularmente como aroeira, que ocorre naturalmente no Brasil, na Bolívia, no Paraguai e na Argentina (Santin \& Leitão Filho, 1991). No Brasil, ocorre desde o Ceará até o Paraná e Mato Grosso do Sul, sendo mais freqüente na Região Nordeste (Lorenzi, 1992). A planta é decídua, heliófila e seletiva xerófila, característica de terrenos secos e rochosos, e ocorre em agrupamentos densos, tanto em formações abertas e secas, como em formações fechadas e úmidas (Lorenzi, 1992; Carvalho, 1994).

A aroeira produz madeira de grande resistência mecânica, de múltiplo uso (Lorenzi, 1992; Carvalho, 1994), e pertence ao grupo ecológico das espécies secundárias tardias (Carvalho, 1994; Ferretti et al., 1995). Apesar da importância econômica e ecológica da espécie, as informações científicas sobre a germinação de suas sementes se restringem a estudos de armazenamento
(Carmello-Guerreiro \& Paoli, 1999). Assim, este trabalho foi concebido com o propósito de estudar o comportamento germinativo das sementes de aroeira submetidas a diferentes condições de luz e de temperatura.

\section{MATERIAL E MÉTODOS}

As sementes de Myracrodruon urundeuva (aroeira) utilizadas neste trabalho foram colhidas na região de Patos (PB), em agosto de 1999, e enviadas para a Universidade Estadual Paulista (UNESP), em Jaboticabal (SP). Nessa instituição, as sementes permaneceram armazenadas em câmara seca $\left(10^{\circ} \mathrm{C}\right.$ e $60 \%$ UR) até a instalação dos experimentos, em agosto de 2000.

Os testes de germinação foram conduzidos em germinadores regulados para os regimes de temperaturas constante e alternada. Em temperatura constante, as sementes foram expostas a valores que variaram de $10 \mathrm{a}$ $40^{\circ} \mathrm{C}$, com intervalos de $5^{\circ} \mathrm{C}$. Em temperatura alternada, foram testadas as amplitudes térmicas de 5,10 e $15^{\circ} \mathrm{C}$, tendo como temperatura mais baixa $20^{\circ} \mathrm{C}(20-25,20-30$ e 20-35 ${ }^{\circ} \mathrm{C}$ ). Nos dois regimes de temperatura as sementes foram submetidas ao escuro contínuo e ao fotoperíodo de oito horas. A luz foi fornecida por lâmpadas fluorescentes de $20 \mathrm{w}$ (luz branca) localizadas no interior dos germinadores, e no caso das temperaturas alternadas o período luminoso correspondeu à temperatura mais elevada.

Foram utilizadas quatro repetições de 25 sementes para cada tratamento, colocadas no interior de caixas plásticas transparentes de 11 x $11 \mathrm{~cm}$, com tampa, forradas com papel-filtro previamente umedecido com $10 \mathrm{ml}$ de solução de nistatina a $0,2 \%$. Sob fotoperíodo foram utilizadas caixas transparentes, e para obtenção de escuro contínuo foram utilizadas caixas de coloração preta.

O período de duração dos testes de germinação foi de 30 dias e as contagens de sementes germinadas, tendo como critério a emissão da raiz primária com comprimento igual ou maior que $0,5 \mathrm{~cm}$, foram efetuadas diariamente. Para os tratamentos referentes à ausência de luz, as contagens foram feitas sob luz verde de segurança (luz branca filtrada por placa acrílica de coloração verde).

Foram determinadas a porcentagem, a velocidade e a freqüência relativa de germinação, utilizando a metodologia descrita por Labouriau \& Agudo (1987). Foi considerada ótima a condição que proporcionou o maior valor de porcentagem e velocidade de germinação, bem como a melhor distribuição da germinação. 
Foi adotado o delineamento experimental inteiramente casualizado, e as análises de variância foram efetuadas em três etapas, sob esquema fatorial. Na primeira etapa foram analisadas as temperaturas constantes (fatorial 7 x 2) e na seguinte, as alternadas (fatorial 3 x 2). Na terceira etapa, a melhor temperatura constante foi comparada com a melhor alternada, nas duas condições de luz, sob o esquema fatorial $2 \times 2$. Os dados de porcentagem foram transformados em arco-seno, para normalização de sua distribuição, no entanto nas figuras eles estão expressos sem transformação. A comparação entre as médias foi feita com a aplicação do teste de Tukey, a 5\% de probabilidade.

\section{RESULTADOS E DISCUSSÃO}

No regime de temperatura constante verificou-se efeito significativo da luz e da temperatura na porcentagem de germinação das sementes de Myracrodruon urundeuva (aroeira), sendo a interação entre esses dois fatores também significativa.

As sementes germinaram em maior porcentagem na ausência de luz (Figura 1A), podendo ser consideradas fotoblásticas negativas, de acordo com Labouriau (1983). Esse caráter foi apenas quantitativo, uma vez que as sementes germinaram tanto na presença como na ausência de luz. Quando adotado o critério de Klein \& Felippe (1991), elas podem ser consideradas fotoblásticas negativas preferenciais.

Comportamento semelhante ao da aroeira foi constatado por Silva \& Aguiar (1998) em sementes de Ocotea catharinensis Mez (canela-preta). Por outro lado, Silva \& Matos (1998) classificaram as sementes de Triplaris surinamensis Cham. (coaçu) de fotoblásticas positivas preferenciais porque, apesar de germinarem em maior porcentagem sob luz branca, apresentaram expressiva germinação na ausência de luz.

Nas duas condições de luz testadas, as sementes de aroeira não germinaram a 10 e a $40{ }^{\circ} \mathrm{C}$, no entanto germinaram entre 15 e $35^{\circ} \mathrm{C}$ (Figura 1A). Esse comportamento indica que a temperatura mínima para germinação encontra-se na faixa de 10 a $15^{\circ} \mathrm{C}$ e a temperatura máxima na faixa de 35 a $40^{\circ} \mathrm{C}$. Os resultados obtidos concordam com a afirmação de Okusanya (1978), segundo a qual as sementes de espécies tropicais são tolerantes à alta temperatura, apresentando limite máximo igual ou superior a $35^{\circ} \mathrm{C}$, porém sensíveis à baixa temperatura, com limite mínimo superior a $5{ }^{\circ} \mathrm{C}$.
Para velocidade de germinação, as sementes de aroeira mostraram-se indiferentes à luz e a interação entre luz e temperatura não foi significativa. $\mathrm{O}$ único efeito significativo foi constatado para o fator temperatura. Nas duas condições de luz testadas, as sementes germinaram mais lentamente a $15{ }^{\circ} \mathrm{C}$ e mais rapidamente a $35^{\circ} \mathrm{C}$ (Figura 1B). Nesta última temperatura, entretanto, a porcentagem de germinação foi inferior (Figura 1A). Os polígonos de freqüência relativa ilustram a lenta e irregular germinação das sementes a $15^{\circ} \mathrm{C}$ e a baixa porcentagem de germinação a $35^{\circ} \mathrm{C}$, tanto na presença (Figura 2A) como na ausência (Figura 2B) de luz.

Em temperatura mais baixa, o metabolismo é reduzido e a semente pode germinar em período mais longo (Amaral \& Paulilo, 1992). Por outro lado, em temperatura mais elevada a velocidade de absorção de água e das reações
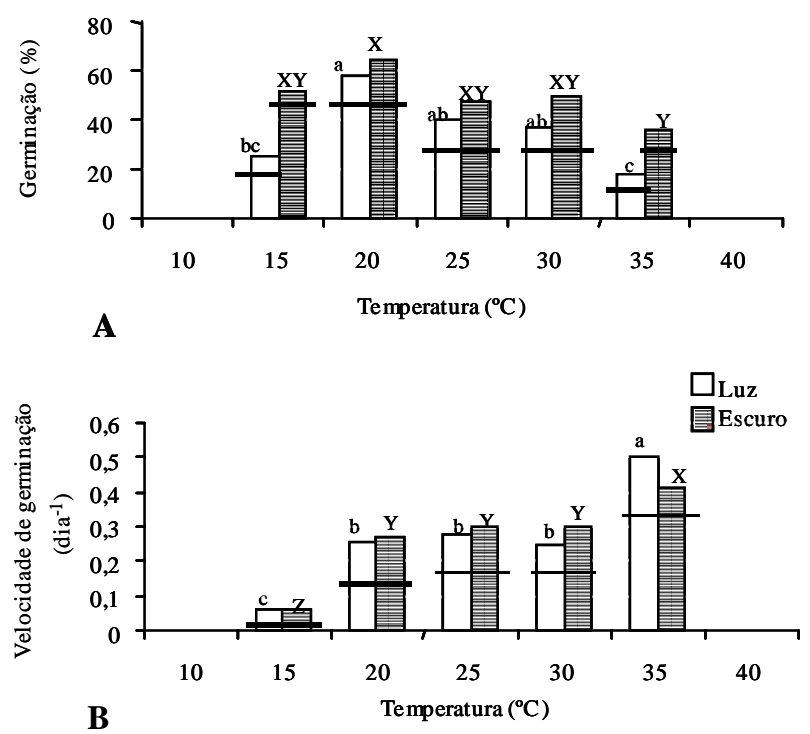

Figura 1 - Porcentagem (A) e velocidade (B) de germinação de sementes de Myracrodruon urundeuva na presença e ausência de luz, sob diferentes temperaturas constantes. Letras minúsculas $(a, b, c)$ compararam médias de temperatura na presença de luz e maiúsculas $(X, Y, Z)$ na ausência de luz. Para cada temperatura, tratamentos de luz unidos pela mesma barra horizontal não diferem entre si. Nível de significância (teste de Tukey): $5 \%$.

Figure 1 - Germination percentage $(A)$ and speed $(B)$ of Myracrodruon urundeuva seeds in presence and absence of light, at different constant temperatures. Small letters $(a, b, c)$ compare means of temperature in presence of light, and capital letters $(X, Y, Z)$ in absence of light. For each temperature, treatments of light linked by the same horizontal bar do not differ. Significancy level (Tukey test): $5 \%$.

R. Árvore, Viçosa-MG, v.26, n.6, p.691-697,' 2002 
químicas é maior, e as sementes germinam mais rapidamente (Carvalho \& Nakagawa, 2000). Estes autores ressaltaram que a temperatura ótima para germinação total é diferente da ótima para velocidade de germinação das sementes.

A faixa de 20 a $30^{\circ} \mathrm{C}$ pode ser considerada ótima para germinação das sementes de aroeira, na qual se

A
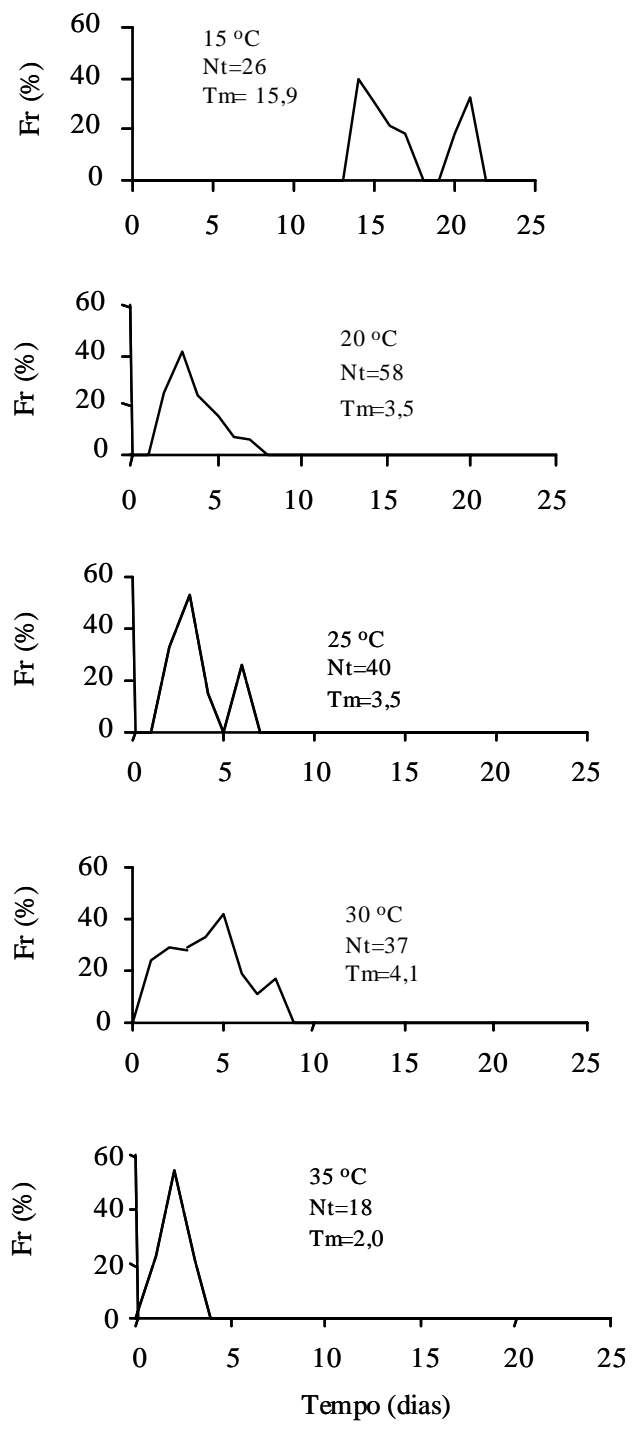

obteve elevada porcentagem de germinação, nos dois ambientes de luz. Dentro dessa faixa não foi constatada diferença significativa entre as temperaturas constantes testadas, tanto para a porcentagem (Figura 1A) como para a velocidade (Figura 1B) de germinação das sementes. Pequena vantagem foi observada a $20^{\circ} \mathrm{C}$, não apenas com relação à porcentagem (Figura $1 \mathrm{~A}$ ), mas também com relação à distribuição (Figura $2 \mathrm{~A}$ e B) da germinação.

\section{B}
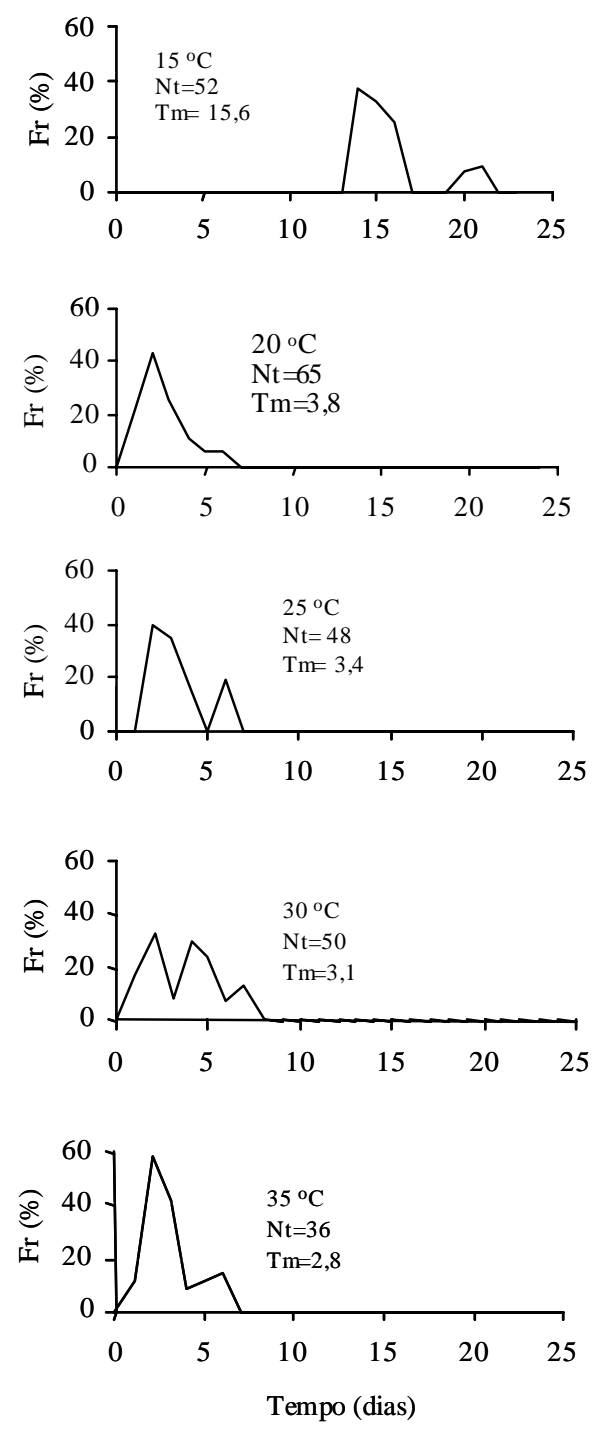

Figura 2 - Distribuição da freqüência relativa (Fr) de germinação de sementes de Myracrodruon urundeuva sob temperaturas constantes, na presença (A) e ausência (B) de luz ( $\mathrm{Nt}=$ número total de sementes germinadas e $\mathrm{Tm}=$ tempo médio de germinação).

Figure 2 - Distribution of germination relative frequency of Myracrodruon urundeuva seeds at constant temperatures, in presence $(A)$ and absence $(B)$ of light $(N t=$ total number of germinated seeds; Tm= mean time of germination). 
Ao trabalhar com sementes de três espécies do gênero Tibouchina, Andrade (1995) constatou, sob fotoperíodo de oito horas, maior porcentagem de germinação na faixa de 20 a $30^{\circ} \mathrm{C}$ para $T$. benthamiana Cogn. e T. moricandiana (DC.) Baill. e de 15 a $30^{\circ} \mathrm{C}$ para T. grandiflora, mostrando a variação entre espécies de um mesmo gênero. Na ausência de luz, entretanto, a germinação foi nula para as três espécies, cujas sementes foram consideradas fotoblásticas positivas absolutas.

As sementes de aroeira revelaram ser fotoblásticas negativas na faixa de germinabilidade (de 15 a $35^{\circ} \mathrm{C}$ ), mas a preferência pelo escuro foi menor na faixa de temperatura ótima (de 20 a $30^{\circ} \mathrm{C}$ ), como pode ser observado na Figura 1A. A 15 e a $35^{\circ} \mathrm{C}$ a germinação no escuro foi significativamente superior à obtida na presença de luz. No caso das sementes fotoblásticas positivas, o requerimento de luz para germinação diminui à medida que se aproxima da temperatura ótima, como verificaram Silva et al. (1997) para Esenbeckia leiocarpa Engl. (guarantã).

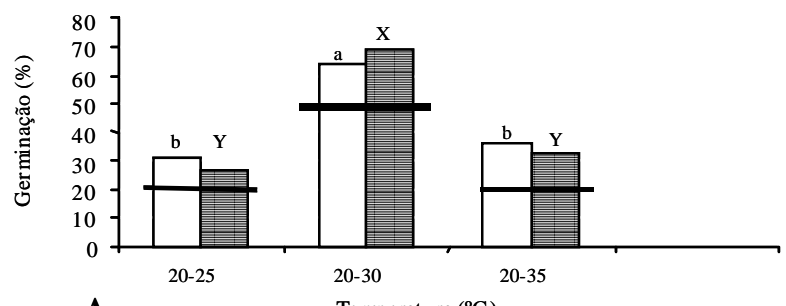

$\mathbf{A}$

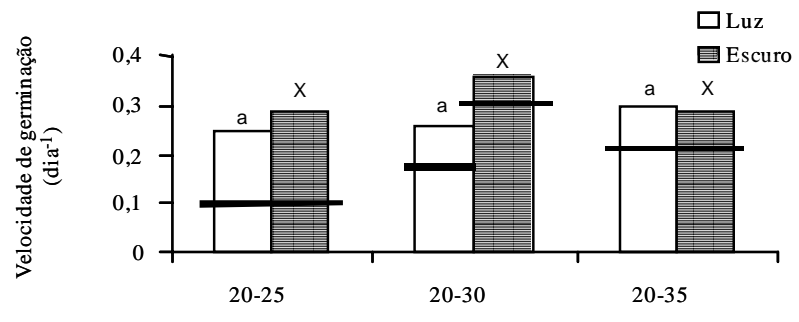

B

Temperatura $\left({ }^{\circ} \mathrm{C}\right)$

Figura 3 - Porcentagem (A) e velocidade (B) de germinação de sementes de Myracrodruon urundeuva na presença e ausência de luz, sob diferentes temperaturas alternadas. Letras minúsculas $(a, b)$ comparam médias de temperatura na presença de luz e maiúsculas $(\mathrm{X}, \mathrm{Y})$ na ausência de luz. Para cada temperatura, tratamentos de luz unidos pela mesma barra horizontal não diferem entre si. Nível de significância (teste de Tukey): $5 \%$.

Figure 3 - Germination percentage $(A)$ and speed (B) of Myracrodruon urundeuva seeds in presence and absence of light, at different alternating temperatures. Small letters $(a, b)$ compare means of temperature in presence of light, and capital letters $(X, Y)$ in absence of light. For each temperature, treatments of light linked by the same horizontal bar do not differ. Significancy level (Tukey test): $5 \%$.
Quando as sementes de aroeira foram submetidas à alternância de temperatura, as sementes revelaram ser indiferentes à luz e a interação entre os dois fatores não foi significativa para a porcentagem de germinação (Figura 3A). Foi constatado efeito significativo da temperatura, tendo a amplitude de $10{ }^{\circ} \mathrm{C}\left(20-30{ }^{\circ} \mathrm{C}\right)$ conduzido à maior porcentagem de germinação do que as amplitudes de $5{ }^{\circ} \mathrm{C}\left(20-25^{\circ} \mathrm{C}\right)$ e $15^{\circ} \mathrm{C}\left(20-35^{\circ} \mathrm{C}\right)$.

Na melhor temperatura alternada $\left(20-30^{\circ} \mathrm{C}\right)$, as sementes de aroeira germinaram mais rapidamente na ausência de luz (Figura 3B), reforçando o fotoblastismo negativo já observado em temperatura constante. Nas outras duas temperaturas alternadas, não houve efeito da luz na velocidade de germinação das sementes.

Ao analisar a distribuição da frequiência relativa da germinação na presença de luz, maior homogeneidade foi obtida a $20-30{ }^{\circ} \mathrm{C}$ (Figura 4A). Constataram-se dois picos de germinação com as outras duas amplitudes e atraso da germinação com a menor amplitude térmica (20-25 $\left.{ }^{\circ} \mathrm{C}\right)$. Na ausência de luz, a germinação foi homogeneamente distribuída nas três temperaturas testadas, mas a $20-30{ }^{\circ} \mathrm{C}$ o número de sementes germinadas foi maior (Figura 4B).

As sementes de aroeira, portanto, germinaram em ampla faixa de temperatura constante e em diferentes amplitudes de temperatura alternada, na presença e ausência de luz. Para Whatley \& Whatley (1982), essa capacidade pode ter consequiências úteis, pois pelo menos algumas sementes devem germinar, qualquer que seja a condição do ambiente onde elas se encontram.

Quando os resultados obtidos na melhor temperatura constante $\left(20^{\circ} \mathrm{C}\right)$ foram comparados com os obtidos na melhor temperatura alternada $\left(20-30^{\circ} \mathrm{C}\right)$, o comportamento germinativo das sementes foi similar: não houve efeito significativo do regime de temperatura e da condição de luz e a interação entre esses dois fatores não foi significativa para porcentagem e velocidade de germinação. Esse comportamento mostra que as sementes de aroeira podem germinar bem tanto em condições de clareiras, onde há incidência direta da luz solar e flutuação diária da temperatura, como em condições de sub-bosque, onde predominam luz difusa e menor amplitude térmica. Assim, os resultados obtidos neste trabalho confirmam o enquadramento da espécie no grupo ecológico das oportunistas ou secundárias tardias.

R. Árvore, Viçosa-MG, v.26, n.6, p.691-697,' 2002 
A
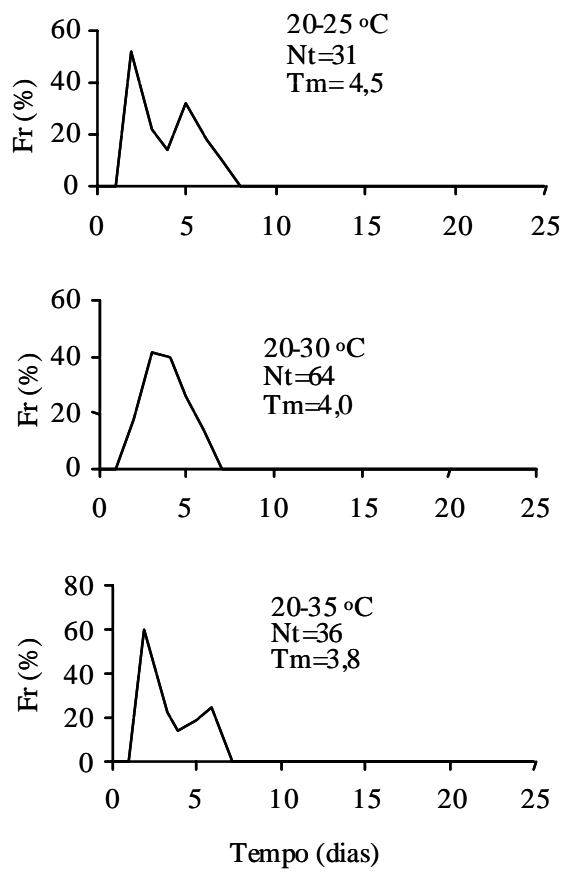

B
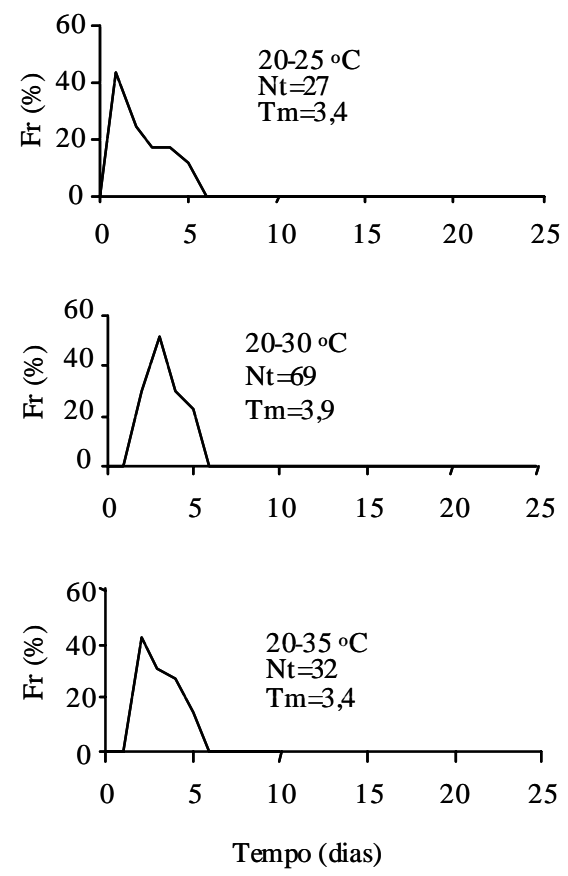

Figura 4 - Distribuição da freqüência relativa (Fr) de germinação de sementes de Myracrodruon urundeuva sob temperaturas alternadas, na presença (A) e ausência $(\mathrm{B})$ de luz $(\mathrm{Nt}=$ número total de sementes germinadas e Tm $=$ tempo médio de germinação).

Figure 4-Distribution of germination relative frequency of Myracrodruon urundeuva seeds at alternating teperatures, in presence $(A)$ and absence $(B)$ of light $(N t=$ total number of germinated seeds; Tm = mean time of germination).

Vale ressaltar que as sementes utilizadas neste trabalho foram colhidas no Estado da Paraíba e permaneceram armazenadas em câmara seca por um ano. Considerando que a espécie ocorre naturalmente desde o nordeste até o sul do Brasil, é importante a realização de pesquisas para verificar o comportamento das sementes procedentes de regiões com características ecológicas diferentes. Da mesma forma, é importante investigar o comportamento germinativo de sementes recém-colhidas, bem como armazenadas por outros períodos e em outros ambientes.

\section{CONCLUSÕES}

- As sementes de Myracrodruon urundeuva revelaram ser fotoblásticas negativas preferenciais.

- As temperaturas mínima e máxima para germinação das sementes encontram-se entre 10 e $15^{\circ} \mathrm{C}$ e entre 35 e $40{ }^{\circ} \mathrm{C}$, respectivamente.

R. Árvore, Viçosa-MG, v.26, n.6, p.691-697, 2002
- No regime de temperatura constante, a faixa ótima para germinação das sementes foi de 20 a $30^{\circ} \mathrm{C}$.

- No regime de temperatura alternada, a melhor flutuação térmica para germinação das sementes foi de $20-30^{\circ} \mathrm{C}$.

- As sementes apresentaram bom comportamento germinativo nos dois regimes de temperatura, na presença e ausência de luz.

\section{REFERÊNCIAS BIBLIOGRÁFICAS}

AMARAL, L. I. V.; PAULILO, M. T. F. Efeito da luz, temperatura, regulador de crescimento e nitrato de potássio na germinação de Miconia cinnamomifolia (DC.) Naudim. Insula, n. 21, p. 59-86, 1992.

ANDRADE, A. C. S. Efeito da luz e da temperatura na germinação de Leandra breviflora Cogn., Tibouchina benthamiana Cogn., Tibouchina grandiflora Cogn. e Tibouchina moricandiana (DC.) Baill. (Melastomataceae). Revista Brasileira de Sementes, v. 17, n. 1, p. 29-35, 1995. 
BEWLEY, J. D.; BLACK, M. Seeds: physiology of development and germination. New York: Plenum Press, 1994. $445 \mathrm{p}$.

CARMELLO-GUERREIRO, S. M.; PAOLI, A. A. S. Aspectos morfológicos e anatômicos da semente de aroeira (Myracrodruon urundeuva Fr. Allem.-Anacardiaceae), com notas sobre paquicalaza. Revista Brasileira de Sementes, v. 21, n. 1, p. 222-228, 1999.

CARVALHO, N. M.; NAKAGAWA, J. Germinação de sementes. In: CARVALHO, N.M., NAKAGAWA, J. Sementes: ciência, tecnologia e produção. 4.ed. Jaboticabal: FUNEP, 2000. p. 128-166.

CARVALHO, P. E. R. Espécies florestais brasileiras: recomendações silviculturais, potencialidades e uso da madeira. Colombo: EMBRAPA-CNPF, 1994. 640 p.

DIAS, L. A. S.; KAGEYAMA, P. Y.; ISSIKI, K. Qualidade de luz e germinação de sementes de espécies arbóreas tropicais. Acta Amazonica, v. 22, n. 1, p. 79-84, 1992.

FERRETTI, A. R. et al. Classificação das espécies arbóreas em grupos ecológicos para revegetação com nativas no estado de São Paulo. Florestar Estatístico, v. 3, n. 7, p. 73-77, 1995.

JESUS, R. M.; PIÑA-RODRIGUES, F. C. M. Programa de produção e tecnologia de sementes florestais da Florestas Rio Doce S.A.: uma discussão dos resultados obtidos. In: SIMPÓSIO BRASILEIRO SOBRE TECNOLOGIA DE SEMENTES FLORESTAIS, 2., 1989, Atibaia. Anais... São Paulo: Instituto Florestal, 1991. p. 59-86.

KAGEYAMA, P. Y.; VIANA,V. M. Tecnologia de sementes e grupos ecológicos de espécies arbóreas tropicais. In: SIMPÓSIO BRASILEIRO SOBRE TECNOLOGIA DE SEMENTES FLORESTAIS, 2., 1989, Atibaia. Anais... São Paulo: Instituto Florestal, 1991. p. 197-215.

KLEIN, A.; FELIPPE, G. M. Efeito da luz na germinação de sementes de ervas invasoras. Pesquisa Agropecuária Brasileira, v. 26, n. 7, p. 955-966, 1991.

LABOURIAU, L. G. A germinação das sementes. Washington: Secretaria Geral da OEA, 1983. 173 p.

LABOURIAU, L. G.; AGUDO, M. On the physiology of seed germination in Salvia hispanica L. I. Temperature effects. Anais da Academia Brasileira de Ciências, v. 59, n. 1, p. 37-69, 1987.
LABOURIAU, L. G.; PACHECO, A. On the frequency of isothermal germination in seeds of Dolichos biflorus $\mathrm{L}$. Plant \& Cell Physiology, v. 19, n. 3, p. 507-512, 1978.

LORENZI, H. Árvores brasileiras: manual de identificacão e cultivo de plantas arbóreas nativas do Brasil. Nova Odessa: Plantarum, 1992. 382 p.

MALAVASI, M. M. Germinação de sementes. In: PIÑARODRIGUES, F. C. M. (Coord.). Manual de análise de sementes florestais. Campinas: Fundação Cargill, 1988. p. 25-40.

OKUSANYA, O. T. The effect of light and temperature on the germination and growth of Luffa aegyptiaca. Physiology Plantarum, v. 44, p. 429-433, 1978.

SANTIN, D. A.; LEITÃO FILHO, H. F. Restabelecimento e revisão taxonômica do gênero Myracrodruon Freire Allemão (Anacardiaceae). Revista Brasileira de Botânica, v. 14, p. 133-145, 1991.

SILVA, A.; AGUIAR, I. B. Germinação de sementes de canela-preta (Ocotea catharinensis Mez - Lauraceae) sob diferentes condições de luz e temperatura. Revista do Instituto Florestal, v. 10, n. 1, p. 17-22, 1998.

SILVA, A. et al. Interação de luz e temperatura na germinação de sementes de Esenbeckia leiocarpa Engl. (guarantã). Revista do Instituto Florestal, v. 9, n. 1, p. 5764, 1997.

SILVA, L. M. M.; MATOS, V. P. Efeito da luz e da temperatura na germinação de sementes de coaçu (Triplaris surinamensis Cham.). Revista Brasileira de Engenharia Agrícola e Ambiental, v. 2, n. 1, p. 94-96, 1998.

SMITH, H. Light quality and germination: ecological implications. In: HEYDECHER, W. Seed ecology. London: Buttrworth, 1975. p. 131-219.

VÁZQUEZ-YANES, C.; OROZCO-SEGOVIA, A. Fisiología ecológica de las semillas de árboles de la selva tropical. Ciência, v. 35, p. 191-201, 1984.

WHATLEY, J. M.; WHATLEY, F. R. A luz e a vida das plantas. São Paulo: EPU-EDUSP, 1982. 101 p.

R. Árvore, Viçosa-MG, v.26, n.6, p.691-697,' 2002 